\title{
Formação médica, racionalidade e experiência
}

\author{
Rationality and experience in medical education
}

Alícia Navarro de Souza 1

\footnotetext{
1 Departamento de Psiquiatria e Medicina Legal da Faculdade de Medicina da Universidade Federal do Rio de Janeiro. Av. Brigadeiro Trompowsky, s/n. Hospital Universitário - 11o andar - 21941-000 Ilha do Fundão Rio de Janeiro - RJ. alicia@ax.apc.org
}

\begin{abstract}
This paper is the result of an experience in a discussion group, in which medical students discussed their first experiences in clinical practice. The research made in the analysis of the discourse of this discussion group isolated themes using the dialogical principle of Bakhtin and Perelman's theory of argumentation, and went beyond the anatomoclinical and epidemiological rationality as it used the operational value of psychoanalytic concepts to the interpretation and deconstruction of the meanings produced in an intersubjective field. The resulting interpretations in our pedagogical experience - which cannot be said unique or exclusive - shows how this experience can contribute to a critical analysis in maintaining the tension and the production of knowledge between diseased and disease, and can furthermore influence medical formation in a highly complex practice by its opposition to any reductive thinking of an exclusive knowledge about pathology and disease. Key words Medical education, Clinical rationality and experience, Medical discourse
\end{abstract}

Resumo Este trabalho decorre de experiência pedagógica e de investigação sobre o aprendizado da clínica por estudantes de medicina. Constitui-se de uma experiência intersubjetiva, que vai além da racionalidade anátomoclínica e epidemiológica, a partir do processo de socialização destes estudantes, quando seus ideais do que seja ser médico confrontam-se com os valores instituídos de uma prática normalizada. Trabalha com a concepção de sujeito a partir da psicanálise, valoriza a escuta de conflitos experimentados por aprendizes da clinica ao vivenciarem a tensão doente/doença, busca sustentar esta tensão e manter a argumentação possivel no contexto de uma experiência pedagógica. Tenta também preservar a complexidade da clínica. Realiza uma análise de discurso fundada no princípio dialógico de Bakhtin. Trabalha com a teoria da argumentação de Perelman. Chega a interpretações que, sem pretenderem ser únicas ou exclusivas, enriquecem a crítica e podem influenciar a formação dos médicos em uma prática extremamente complexa e difícil, não redutivel à aplicação de um saber exclusivamente sobre a doença.

Palavras-chave Formação médica, Racionalidade e experiência clínicas, Discurso médico 


\section{Questionando uma prática}

Este trabalho é fruto da reflexão sobre um malestar que experimento no trabalho que venho realizando, há vinte anos, no campo de psicologia médica. A psicologia médica, tendo como objeto o campo dinâmico da relação médico-paciente, é uma prática interdisciplinar institucionalizada, na qual se encontra permanentemente colocado o desafio de se manter em tensão o saber sobre a doença e o saber sobre a relação com o doente, o que só é possível quando, na clínica, o médico vivencia a experiência de incompletude do modelo médico ao exercer a função médica no caso singular. Tem de haver a dúvida produtiva na experiência de incompletude em relação ao saber médico para que se crie um espaço para um outro saber.

Refletindo sobre minha prática diria, sucintamente, que na atividade docente-assistencial realizada no cotidiano de enfermarias clínicas, observo uma diminuição da tensão produtiva nos encontros com estudantes e médicos na cena clínica, os quais atualmente sabem menos sobre seus pacientes e estão menos implicados na relação com eles. Nos últimos anos, fomos neutralizados na posição de especialistas. Especialistas em pacientes com "alteração de comportamento", "depressão", "ansiedade" - expressões freqüentemente usadas nos pedidos de parecer - e, supostamente, especialistas em sofrimento quando, nos pareceres, nos solicitam um "acompanhamento do paciente" após fazer referência a uma situação clínica que implica ameaça, limitações, enfim, sofrimento. Somos predominantemente vistos como os psiquiatras de hospital geral, os quais detêm um olhar sobre as reações de pacientes em termos do normal e do patológico, portanto, diagnósticos a fazer, tratamentos especializados a instituir.

$\mathrm{Na}$ sala de aula, como professora da disciplina obrigatória de psicologia médica, a cada início de semestre, vivo o desafio renovado de pretender um diálogo produtivo com os alunos. Todo semestre há sempre algumas vozes a nos dizer: "isso é tudo subjetivo"... “é uma questão de bom senso"... "os médicos não têm tempo para ouvir os pacientes"... "sempre ouvi que na psicologia médica é tudo viagem”... E o desafio se mostra quase intransponível em relação àqueles que, no início do curso, nos transmitem um bem-estar, um sentimento de certeza, uma convicção de que não há ali nada de realmente importante a ser aprendido ou a ser discutido conosco. Os textos de Eizirik (1994), Zaidhaft (1997) e Muniz e Chazan (1992), professores de psicologia médica de três instituições públicas de ensino médico de nosso país, também nos falam das dificuldades deste ensino e poderíamos dizer que há uma crise nesse campo, onde o professor se confronta com os alunos quase cooptados por um pragmatismo, que exclui qualquer outro valor que não o da eficácia da ação e desconsidera o valor de verdade no discurso, como desconsidera o valor da palavra. Por outro lado, na avaliação do curso realizada ao fim do semestre, não raro alguns alunos se dizem "surpreendidos" no sentido do curso ter superado suas expectativas e, também, há sempre alguns que sugerem a continuidade do curso.

Valorizando esta demanda de alunos, que nos pareceu especialmente associada à experiência nova de assunção de pacientes, considerando o nosso interesse de investigar as vicissitudes no diálogo sistemático com um professor de clínica médica e alunos durante o ciclo clínico e, ainda, aproveitando a oportunidade institucional que a reforma curricular introduziu, propusemos uma disciplina eletiva - Reflexão sobre a Prática Médica. Essa disciplina consiste num grupo de discussão que, sem pretensão de fornecer conteúdos teóricos preestabelecidos, coordenado por nós com a colaboração de um professor do Departamento de Clínica Médica, centra-se na experiência clínica dos alunos, nas situações por eles vividas na relação com o paciente, sua família e a equipe de saúde.

Oferecida desde 1992, observamos que a demanda à disciplina Reflexão sobre a Prática Médica se restringe basicamente a alunos do 6o e 7o períodos, apesar de nela poderem se inscrever alunos de quaisquer períodos a partir do 6o período. Pensamos que essa demanda refere-se à experiência de desamparo pelo confronto com o sofrimento e a morte de seus primeiros pacientes associada a um saber reconhecidamente mais limitado que esses estudantes de 6 o e 7 o períodos possuem. Esse momento da formação médica é reconhecido por vários autores como uma fase de maior intensidade conflitiva. Eles se encontram praticamente no início do ciclo profissional e constituem o grau inferior na hierarquia da equipe médica de uma enfermaria clínica e, portanto, ainda muito vulneráveis às incertezas e às situações angustiantes da prática clí- 
nica. Esses alunos ao integrarem pela primeira vez uma equipe de saúde estão assim convocados a participar do exercício da função médica, que não depende apenas dos conhecimentos calcados na racionalidade anátomoclínica (Foucault, 1977a), mas também de uma série de valores que atravessam e constituem a prática médica, permitindo que os médicos se reconheçam como pertencendo a um grupo social.

A formação médica, lugar de transmissão do saber e lugar privilegiado de reprodução da prática médica, passa, além da aquisição de conteúdos e habilidades técnicas, pela apreensão do cenário social onde se desenrola a prática assistencial institucionalizada e pela busca de uma identificação do aluno com o seu professor. É sobretudo nas atividades práticas em ambulatórios e enfermarias, sob responsabilidade das várias disciplinas clínicas e cirúrgicas, que o aluno, de maneira implícita e sem qualquer clareza de consciência, vai construindo sua identidade profissional no que concerne aos valores sociais de uma prática com suas implicações no modo de vivenciar e realizar essa prática. Alguma coisa acontece para transformar o olhar e a escuta curiosa e inquieta de tão jovens estudantes dos primeiros anos em uma busca obstinada de aquisição de conhecimento e habilidades técnicas. A demanda espontânea à disciplina eletiva, restrita a alunos do 6o e 7o períodos, pode em parte ser compreendida, como um indicador dessa transformação, sendo importante assinalar que, na estrutura curricular, os alunos de 8 o e 9o períodos cursam disciplinas referidas a especialidades médicas, quando não lhes é oferecida a oportunidade de vivenciarem a experiência de assunção de pacientes, diferentemente dos estudantes de 6o e 7o períodos.

Já os alunos de 10으, 11ㅇe e 12o períodos se encontram no Internato, que se organiza de forma rotatória nas consideradas quatro grandes áreas (Clínica Médica, Cirurgia, Pediatria e Gineco-Obstetrícia) e, como internos, eles desenvolvem uma experiência clínica intensa em enfermarias e ambulatórios. No entanto, a medicina, para os quase médicos, não parece ser pensada, de forma predominante, como uma prática social onde tudo ganha sentido, mas sim como uma prática de sentido único, qual seja, uma oportunidade de exercício de um saber/poder que cura, controla ou reduz as manifestações das doenças, cujos sucessos maiores ou menores, referidos ao valor de efi- cácia da ação sobre a doença, são unicamente dependentes do estágio de desenvolvimento de um conhecimento técnico, passível de ser aprendido nos últimos artigos publicados e no trabalho com profissionais mais experientes, onde as dúvidas e incertezas se redimem e a angústia do desconhecimento tem seu horizonte de finitude. A especialização do conhecimento médico colabora, evidentemente, para o sonho do domínio total de um determinado campo de conhecimento e para a atomização da prática médica, cada vez mais reduzida a uma intervenção imediata de uma técnica sobre um pedaço de corpo, sobre um corpo fragmentado, como se nada fosse mediado pela relação entre os sujeitos sociais dessa prática.

\section{A pesquisa e o referencial teórico-metodológico escolhido}

A psicologia médica, tendo como suporte teórico predominante a teoria psicanalítica, pretende realizar um trabalho sobre demandas de estudantes ou médicos impossíveis de serem pensadas no modelo médico estrito. No entanto, a expressão e a escuta dessas demandas e o trabalho compartilhado que se pode realizar no ensino e na prática da clínica, pelas dificuldades que apontamos, está a exigir a articulação de conceitos psicanalíticos a outros referenciais teóricos, de forma a compreender as condições de possibilidade da prática discursiva de professores psicanalistas num hospital de ensino, onde pretendemos uma ação pedagógica que incida sobre a relação médico/estudante/paciente. Contextualizando assim as relações pedagógicas e assistenciais num particular exercício da prática médica onde estão presentes as relações de poder hierarquizadas de um hospital de ensino, lançamos mão da teoria analítica de Foucault (1977b) sobre o poder disciplinar, em articulação com sua investigação sobre a constituição do saber médico moderno, para podermos melhor compreender as coerções do discurso a que estão submetidos os sujeitos no sistema institucional da medicina (Foucault, 1996).

Considerando que a prática de um psicanalista professor de psicologia médica não é uma prática de psicanálise senso estrito ou "em intensão", não podemos pretender a interpretação de formações inconscientes de estudantes ou médicos, mas sim possibilitar um ques- 
tionamento de suas posições subjetivas quando, atentos às suas demandas, nos expressam conflitos em uma experiência que pretende ser pedagógica e não pode silenciar ou banalizar o sofrimento. Nessa ação pedagógica de profissionais de psicologia médica, mais do que a transmissão de informações, o que está em jogo é a possibilidade de se manter a tensão doente/doença na clínica, propiciando o levantamento de questões que são argumentadas num campo de valores numa perspectiva mais abrangente do que o modelo médico restrito.

Pretendendo com esta pesquisa fazer uma contribuição à formação médica, decidimos investigar o que querem e o que podem querer estudantes de medicina quando, na experiência de aprendizado da clínica, eles se defrontam com a tensão doente/doença no exercício e na apreciação do ato médico, que para além da eficácia da ação se realiza também como ato simbólico (Souza, 1998). Para realizar esta investigação, escolhemos associar um método de pesquisa ao método pedagógico criado na disciplina eletiva Reflexão sobre a Prática Médica, por considerar que:

- a presença sistemática de professores de psicologia e clínica médicas, que falam de diferentes lugares, não só em função de sua experiência profissional como também de sua posição na economia discursiva da instituição, está a exigir a criatividade dos participantes, em especial os alunos, pois não é tão simples para eles pressuporem os acordos possíveis e, assim, anteciparem concordâncias e discordâncias na apreciação da função e do ato médicos;

- o fato de a participação de alunos e professores de clínica médica ser uma escolha espontânea constitui uma oportunidade mais favorável, privilegiada diríamos, para a realização de trocas simbólicas, para a produção de significados entre os participantes, uma vez que estão em jogo não só condições dadas pelas normas da vida institucional, mas o desejo dos participantes de discutirem a clínica e de discutirem com estes interlocutores;

- e, ainda, sendo o professor de clínica médica o modelo preferencial de identificação para o aluno, temos assim neste espaço pedagógico e de pesquisa no questionamento da prática clínica a oportunidade de não fomentar a dissociação doente/doença, contribuindo para a constituição de dois discursos: o do cuidar e o da competência técnica.
O desafio para os profissionais de psicologia médica no ensino e no exercício da clínica, portanto, é e sempre foi o diálogo, a produção de um intertexto, no contexto dialógico que vai além de uma relação entre os interlocutores.

Tanto na Teoria da Enunciação de Bakhtin (1981) como na Teoria da Argumentação de Perelman (1996) a enunciação é sempre função de um auditório social, isto é, de um campo intersubjetivo social e historicamente situado. Podemos aproximar essas teorias com a psicanálise na medida em que o que está em jogo é o sujeito como função da intersubjetividade e o sentido exposto à interpretação se produzindo no trabalho de elaboração discursiva que se faz entre os sujeitos da enunciação.

Considerando o princípio dialógico de Bakhtin valorizamos a produção discursiva que se dá na estrutura de relações do grupo de discussão, campo de nossa pesquisa, pois o relato de situações clínicas neste espaço se coloca dialogicamente em relação às outras apresentações de casos clínicos em contextos mais habituais durante a formação médica. Assim diferentes vozes do contexto de um hospital de ensino se fazem presentes nas falas dos sujeitos da pesquisa, nos possibilitando realizar uma investigação que incide sobre a construção da "identidade" de paciente e da "identidade" de médico, pois o relato oral e escrito de casos clínicos constituem práticas formativas (Good, 1994) onde o aluno aprende não meramente a descrever a realidade, mas a construir a realidade do objeto do olhar e do discurso médicos.

Perelman ao dedicar-se à investigação de uma lógica argumentativa não só nos oferece uma tipologia de acordos e de argumentos, que utilizamos para a análise do discurso, como sua teoria é uma investigação criteriosa do uso da linguagem cotidiana na defesa de idéias, quer referidas ao conhecimento quer à opinião, que importam quando se busca o plausível, o verossímil, o razoável na justificação de uma escolha. A argumentação visa a uma escolha entre possíveis e prepara ou determina uma ação. Para Perelman ela está sempre vinculada a uma preocupação de ordem prática, ela não se desenvolve no vazio mas sim numa situação psicológica e socialmente determinada, ou seja, num contexto particular. É por causa das relações entre ação e argumentação que ela compromete praticamente os que dela participam. Não é possível separar uma afirmação da pessoa que a faz. 
A investigação dos argumentos no processo de apropriação do discurso médico nos possibilita melhor compreender a formação de uma identidade profissional se valorizamos que é na linguagem e pela linguagem que o estudante estrutura a experiência e constitui, para além de um olhar anátomo-clínico, uma perspectiva com a qual exercerá a prática médica.

Nossa pesquisa foi, então, realizada na Faculdade de Medicina/UFRJ, tendo como sujeitos 14 estudantes do 6o (M6) e 7o (M7) períodos do curso médico, três professores do Departamento de Clínica Médica $(\mathrm{CM})$ e a pesquisadora (PSM), professora do Departamento de Psiquiatria e Medicina Legal. Os alunos de 6o e 7o períodos, sujeitos da pesquisa, encontram-se curricularmente em atividades de treinamento, principalmente, no Hospital Universitário Clementino Fraga Filho/UFRJ, passando a maior parte do tempo em suas enfermarias clínicas, onde se desenvolve a parte prática das disciplinas Medicina Clínica II e III, o que propicia a experiência clínica que é objeto de discussão em nossa pesquisa. Os sujeitos da pesquisa reuniram-se em torno da proposta da disciplina “eletiva” Reflexão sobre a Prática Médica, tendo sido realizados 15 seminários, com freqüência semanal, com duração de 1 hora e 30 minutos cada seminário, ao longo do segundo semestre de 1995 . No primeiro seminário, solicitamos aos participantes o seu consentimento para a gravação das discussões, o que nos foi concedido, tendo sido explicitado o nosso interesse de pesquisa em relação à contribuição de professores de Psicologia Médica à formação médica.

Nossa pesquisa se centra no discurso dos alunos como elemento revelador dos conflitos experimentados no processo de apropriação do discurso médico. Estamos assim sendo coerentes com a própria metodologia proposta para a disciplina eletiva, que constituiu o campo de nossa pesquisa, na qual os alunos trazem as situações conflitivas, os temas relacionados à sua experiência clínica, alvo de incerteza, dúvida e angústia para eles.

A simples adesão a uma proposta que implica reuniões semanais durante todo um semestre, sem temas prefixados, nas quais se pretende, com a bússola dos conhecimentos médico e psicanalítico, lidar com o desafio de discutir problemas que alunos experimentam no inesperado de sua aventura clínica, exige uma certa destituição narcísica, que possibilita a participação produtiva nestes grupos de discussão.

A proposta encerra, de alguma forma, a possibilidade de cada participante ser reconhecido na sua singularidade nessa experiência compartilhada. Isso nos parece importante se compreendemos que a possibilidade de se reconhecer a singularidade do paciente e de sua relação com o estudante ou médico é o cerne do discurso da psicologia médica. Pretender que futuros médicos reconheçam a dimensão do sujeito, em cada paciente e em si mesmos, como organizadora do encontro clínico, sem que isso se passe na relação professor-aluno durante a formação médica seria mesmo um paradoxo.

Nesse sentido, estamos falando, a partir da psicanálise, de uma experiência que se passa no campo da formação médica, da transmissão de um saber irredutível ao aprendizado de uma técnica. Estamos no campo da educação realizando uma experiência pedagógica que tem conseqüências no nível simbólico das significações produzidas entre os sujeitos da enunciação, que ficam confrontados com os limites de um saber da técnica e são solicitados para uma prática interpretativa em um campo de significações e valores. Ao valorizarmos que o médico não é mais o mestre de sua medicina mas sim um agente do discurso médico, é a partir da experiência conflitiva dos alunos, envolvendo inclusive seus ideais em relação ao exercício profissional, que podemos investigar a possibilidade de uma prática pedagógica se pondo além da mera formação de técnicos presidida pelo valor de eficácia.

Nossa pesquisa está voltada para o discurso do médico e não para o discurso da medicina entendido como o discurso de uma disciplina. Nesse diálogo entre professores e alunos, o que está em jogo centralmente é a formação da função médica no exercício da clínica. Estamos interessados em investigar a formação dessa identidade médica, na qual professores de clínica médica e psicologia médica estão envolvidos com essa tarefa a partir das falas dos alunos sobre sua experiência clínica, que envolve pacientes e familiares, internos, residentes, médicos não-professores, professores de medicina, enfermeiros, assistentes sociais, enfim todos os membros de uma equipe de saúde de um hospital universitário. Cada um dos participantes confronta suas hipóteses e pressuposições com as réplicas provocadas por sua fala, por sua ação discursiva. $\mathrm{O}$ 
confronto entre os ideais de cada um dos participantes e a práxis está permanentemente em questão nas discussões. As semelhanças e diferenças entre os participantes desse grupo semiótico se expressam nos acordos desse auditório especializado, nas premissas e nos argumentos com suas réplicas de maior ou menor intensidade de adesão ou mesmo de não adesão. Analisamos, através dos argumentos e réplicas, o discurso dos dois professores e o dos alunos em suas semelhanças e diferenças na ação pedagógica, buscando identificar aspectos que facilitam ou dificultam réplicas de adesão entre professores e entre professores e alunos. Cada professor e cada aluno têm suas hipóteses em relação à função médica, ao ato médico, à formação e à prática médicas, enfim ao que seja ser médico em nosso atual contexto histórico e social.

Nossa pesquisa, portanto, objetiva melhor conhecer o processo de socialização do estudante de medicina no que diz respeito à transformação operada durante o curso médico a qual se, por um lado, o torna apto a lidar com o sofrimento através do conhecimento das doenças, por outro, dificulta sua aproximação do sofrimento de um doente através de um distanciamento do senso comum do que seja a medicina e do que seja ser médico, ou seja, de sua representação social que deveria enlaçar os que buscam e os que promovem o alívio do sofrimento que advém do corpo.

\section{A análise do material produzido}

Diante do rico e extenso material de nossa pesquisa, cujo registro totalizou 17 horas de gravação, isolamos interpretativamente quatro temas, ápices multideterminados no dizer de Bakhtin, que se prestaram à análise do discurso. São eles: o sofrimento psíquico, o corpo erotizado, a identidade técnica e a experiência de sujeição.

No primeiro tema, dois casos são apresentados exemplarmente quando os alunos buscam explicitar argumentativamente a regra da desvalorização do sofrimento psíquico.

"Seu” W, um senhor de 72 anos, hipertenso, diabético, internado numa enfermaria de clínica médica há mais de um mês, sendo investigado quanto ao sítio primário de um tumor maligno, cuja metástase óssea na coluna vertebral produz dores que o restringem ao leito, foi avaliado pela equipe responsável co- mo apresentando "demência e labilidade emocional” o que gerou uma prescrição de psicofármacos. Os alunos que o acompanham na enfermaria, mobilizados com a prolongada investigação diagnóstica que não havia ainda possibilitado medidas terapêuticas, trazem o caso ao grupo, por considerarem que "sonhou, já está tomando Haldol”. Do ponto de vista dos alunos, ao medicalizar uma expressão de sofrimento do paciente, a equipe teria imputado a ele um diagnóstico psiquiátrico, cuja medicação teria o efeito não só de acalmá-lo, mas calá-lo num sofrimento que envolvia um protesto justo, tranqüilizando assim a equipe e, ainda, os outros pacientes, que tinham seu sono perturbado pela expressão de sofrimento desse paciente. Como a pesquisadora era também a parecerista responsável pelo posto clínico onde se encontrava "seu" W internado, esta foi pessoalmente à enfermaria avaliar o paciente junto com a equipe, a partir da demanda dos alunos. A pesquisadora considerou possível a hipótese de uma síndrome mental orgânica, no caso uma demência vascular, embora tenha ponderado que o uso de Tylex na dose empregada e a ansiedade do paciente, por sua condição clínica e pelo tempo de internação prolongado sem resultados terapêuticos, deveriam estar importando nas manifestações psicopatológicas de "seu” W. Concordou com a iniciativa da equipe médica quanto ao uso de Haldol em baixas doses, que trouxera alívio sintomático ao paciente, já que esta informava que o paciente havia apresentado efeito paradoxal ao Diazepam.

Seis semanas após o grupo retornar à discussão sobre "seu" W, a pesquisadora levanta a hipótese de que os alunos estariam buscando "evitar o diagnóstico psiquiátrico" pelo quanto ele imputaria de dor ao paciente em função da "desqualificação", do "estigma social”. Com a adesão de alguns alunos a essa hipótese a controvérsia parecia resolvida, quando se inicia a discussão de um outro caso - o de dona $\mathrm{M}-$, mas uma parte dos alunos havia se mantido em silêncio. Após o primeiro fragmento do caso de dona $\mathrm{M}$, a discussão do caso de "seu" W mais uma vez retorna.

O caso da dona M surge, então, como uma tentativa de diminuir a tensão conflitiva do grupo, deslocando o conflito temporariamente para fora, para a cena da enfermaria, quando uma aluna vai buscar a coesão do grupo supondo uma adesão à sua apreciação do caso. E o que se passa em nível argumentativo? A 
aluna introduz o caso clínico de dona $\mathrm{M}$ como um recurso ao caso particular, um exemplo buscado para indicar o ponto de vista sob o qual os fatos anteriores deveriam ser considerados. Nesse contexto argumentativo, ao se aceitar discutir o caso particular, há um acordo prévio referido à possibilidade de, a partir do recurso ao caso particular, se chegar a uma generalização, no caso, a uma regra (Perelman, 1996). A regra a que o grupo chegará é a desvalorização do sofrimento psíquico, "o pouco caso que se faz" nas palavras da aluna ao dizer, no seminário seguinte, porque introduziu o caso dona $\mathrm{M}$.

Dona M havia retornado do CTI, onde foi tratada durante um mês em razão de uma sepsis logo após o segundo ciclo de quimioterapia para leucemia linfóide aguda diagnosticada recentemente.

M7-7 Aí fui ver a dona M. Levei um susto. É uma paciente que mudou completamente a fisionomia, eu não tinha visto ela quase no CTI, e apática, ela era uma pessoa extremamente comunicativa, assim, em choque, eu acho, fiquei chocada.

PSM Em choque que você quer dizer ou chocada?

M7-7 Chocada, mau. E eu mais ainda. (RI)

PSM E você chocada também.

M7-7 Fui para casa, sonhei aquelas coisas todas. Hoje eu voltei lá, e igual, sabe. E ela respondeu a mim, não está respondendo ao médico, ao residente, sabe, e comigo ela tentou sorrir, e eu fiquei bem mexida com isso tudo, fiquei lá um tempão, depois fui conversar com o residente. A gente começou a conversar, ele era o único residente que ela gostava um pouco mais, e ele falou assim: "ela nem respondeu a mim, ela não quis falar comigo". A gente foi falando, falando e ele falou assim: "é, porque eu não tenho coragem de continuar esse tratamento nessa paciente, porque eu acho que é muito sofrimento, mesmo que ela saia dessa é muito sofrimento". Aí eu: "ah é"? Ele: "é, não tenho, mas está todo mundo querendo continuar". O papo foi indo, ele falou assim: "é, porque eu acho que a dona M está deprimida”. Eu falei assim: "eu não acho, eu tenho certeza que ela está muito deprimida, está muito triste". "Ah, você acha?” Mas ele não estava em nenhum momento mostrando que ele estava com certeza disso, ele estava muito inseguro, parecia que ele estava falando uma coisa assim para mim que eu ia cair em cima dele. [...] senti que ele chegou em mim porque ele sabia que eu tinha uma visão diferente em rela- ção a isso. Aí ele falou assim: "é, porque engraçado né, eu falei isso no round...” Ele, no round, com a dona M na frente, ele falou assim: "olha, eu acho que essa paciente está deprimida”. E ele falou assim: "Na hora que eu falei isso no round, me ridicularizaram". Ai falaram-que absurdo! - que "isso aí é uma questão..." - essa foi a palavra que ele usou - “...ridicula”. Eu falei: "ridícula como?!"

Para Perelman (1996), o ridículo desempenha na argumentação um papel análogo ao do absurdo na demonstração e, nesse sentido, ele é a principal arma na argumentação. Uma afirmação é ridícula quando entra em conflito, sem justificação, com uma opinião aceita, uma regra habitualmente admitida. O orador pode até afrontar o ridículo, o que constitui para esse autor uma prova de que a argumentação, diferentemente da demonstração, jamais é coerciva.

A reação de dona $\mathrm{M}$, do residente, de M7-7, o valor do qualitativo, do precário, do singular é, então, amplificado através de um argumento a fortiori:

M7-7 ... Eu falei assim: "é engraçado, então põe a mãe deles - eu falei isso mesmo - põe a mãe deles um mês no CTI e faz um round aqui embaixo e fala que ela não vai estar deprimida. Ele vai estar deprimido junto com ela.

Os alunos falam da incompatibilidade que descobrem no discurso de professores médicos, que enfatizam o escutar o paciente e, ao mesmo tempo, não se colocam disponíveis para ouvir os alunos sobre essa escuta. "Minipsiquiatras", "bobalhões da corte", os alunos se descobrem realizando uma "função" temporária prescrita pelo "esquema”, apesar de um "discurso que é bonito". Falam, assim, de um ideal romântico enunciado no discurso médico e do exercício de uma prática normalizada sem romantismo. Os alunos arriscam-se, vivendo o conflito entre responder à demanda transferencial na relação com o paciente e serem reconhecidos pelos pares como pertencentes ao grupo social, hoje estudantes de medicina, amanhã médicos.

M6-1 Eu tenho medo de alguém da equipe que é superior a mim chegar pra mim e dizer: "ó, pára de conversar aí e vamos começar a fazer exame físico, vamos começar a evoluir o doente".

M7-1 É verdade. Eu também tenho.

M7-6 É cobrado que a gente não tenha muito envolvimento.

M7-2 É cobrado sim. Eu fui falar assim: puxa mas ela 'tá aqui há dois meses e ninguém re- 
solve nada. Aí começa: "Não porque na doença de Crohn parará..." Ninguém me escuta, entendeu?

M6-2 Mas é cobrado, é cobrado de uma forma tão linda, que para a maioria das pessoas isso não é. Porque todo mundo senta cara e conversa e fala: "pô, mas tem que escutar o paciente". Todos eles falam:

M7-6 Mas aí é blá, blá, blá.

M6-2 "Você tem que escutar o paciente, você tem que..., não, o paciente é fundamental. O M6, vocêé o M6, você é aquele cara que tem o contato". Mas na hora de discutir contigo ele não quer saber o que o paciente falou não, mas ele bate o discurso. O discurso é este, o discurso é bonito.

M6-1 É como se fosse uma parte da formação isolada, entendeu. Nessa fase que vocês sabem menos clínica, menos medicina...

M7-2 Pois é. Quando chegar no Internato você não vai mais conversar com ninguém.

M6-1 Você vai ser aquela figura que vai estabelecer uma relação melhor, que vai falar: "Oi! E aí meu amigo...?"

M7-2 É uma função, é uma função. Quando eu chegar no Internato eu vou ter outra função.

M6-2 É toda a discriminação da tarefa do hospital. Nós somos os minipsiquiatras.

PSM Minipsiquiatras!

M6-1 Nós somos os bobalhões da corte.

M6-2 Todo mundo aqui: "pô, não quero conversar contigo não, mas pô tem o M6".

No segundo tema emerge o corpo erotizado que implica inibições, sintomas e angústia. Se o objeto do saber médico é a doença e seu acontecimento num corpo redutível às necessidades biológicas, o objeto de investigação do médico na clínica é, no mínimo, o corpo de um doente, que é, em princípio, erotizável num campo intersubjetivo. Por isso o risco associado a uma maior intensidade de erotização ou sua negação, $a$ "banalização" nas palavras do aluno.

M6-2 E vocêpode levar a coisa pra um outro lado que é... Você fala assim [referindo-se ao professor de clínica médica]: você faz um exame físico, como médico, profissional, num paciente, ausculta, faz tudo, e aí você fica, você perde esse seu profissionalismo na hora do toque. Isso é uma forma de ver a coisa. Você se sente embaraçado. Agora, outra forma de ver que eu acho é a seguinte: quando você vai fazer o toque, você se vê como profissional, e ao contrário, você banaliza, pô, o exame físico de uma paciente. Será que também não é tão complicado, se você for avaliar a moral que 'tá te levando a questionar um toque, você pegar e abrir a blusa da paciente, botar o seu esteto? Isso você faz.

A presunção de que o objeto do médico é exclusivamente um corpo biológico e que essa redução é o que identifica uma "postura profissional" é central na argumentação que pretende calar a inquietação do aluno em sua primeira experiência de realização de um toque retal.

CM-1 ... O toque retal, eu acho que vocês precisam encarar isso da mesma forma que vocês estão palpando um fígado...olhando outros orifícios tipo ouvido, boca, nariz etc. Quer dizer, você não 'tava invadindo o cara, e nem o fato do cara ser homossexual, ele certamente não estava com olhos brilhando. É como você pensar que o toque vaginal é um momento de prazer da mulher. Não é nada disso.

Essa presunção é posta em questão e, ao fim, o grupo chega a uma outra presunção: o toque retal não é realizado com a freqüência devida na medida em que a decisão de sua realização não é determinada só por verdades médicas, mas também por significados inscritos na cultura e na história individual.

CM-1 Quando você pára para pensar, justamente está aí uma clara falha da nossa medicina: você tem os doentes internados, que estão no hospital e não tem toque retal, não tem exame neurológico feito de rotina, não tem exame articular feito de rotina. Então, isso são exames que deveriam ser - e exame de mama e fundo de olho - isso deveria ser feito, porque isso é feito em um monte de lugares, inclusive em alguns hospitais em São Paulo se exige que o residente, o interno, quer dizer, que você faça o exame clínico completo do doente.

No terceiro tema, vemos fatos e verdades médicas na construção de argumentos que engendram a identidade técnica quando, na estrutura dialógica do grupo, foi possível questionar: é uma "norma técnica" que define se houve uma "morte" ou uma "perda fetal", na experiência de uma parturiente e de uma equipe obstétrica? É a existência de uma "síndrome psiquiátrica” que decide a escolha de mostrar ou não o filho morto à mãe? $\mathrm{O}$ conhecimento das doenças tomado como o único e necessário saber para o exercício da medicina limita e inibe o médico e seus aprendizes de viver de modo criativo a tensão doente/doença inerente à clínica, lançando mão de sua humanidade comum que enlaça médicos e pacientes.

A surpresa vivida pela negação da morte e a angústia de desamparo experimentada pe- 
los alunos confrontados com sua vulnerabilidade humana colocam em questão "a frieza da maioria dos médicos", estruturada coletivamente numa identidade eminentemente "técnica”, como defesa em relação à morte. No entanto, da frieza como defesa em relação à morte passa-se rapidamente à frieza com relação à vida, embora não sem conflito.

M7-4 Eu acho que você se acostuma.

M7-2 Se acostuma, isso é verdade.

M7-4 Eu acho, eu faço estágio na maternidade. Eu acho que as primeiras vezes que eu vi um, um natimorto, sabe, ou um abortamento ou, sabe, um neném prematuro, muito prematuro nascer inviável.

M6-1 Ou uma mãe ter que ir embora porque não tem vaga. (Risos)

M7-4 Ou uma mãe ter que ir embora... Exatamente, eles (Referindo-se a M6-1 e M6-2) viram isso, uma mãe ter que ir embora porque não tem vaga, eles 'tavam rodando na matéria eletiva, eu já 'tava lá há muito tempo...

PSM Uma mãe que está prestes a parir?

M6-2 E a gente é que tinha que mandar a mãe embora.

M7-4 No começo eu ficava com isso, eles viram. No começo, quando tinha que mandar uma paciente embora... A chefe do plantão, um dia, chegou pra mim e disse: "M7-4, você não pode ficar internando paciente assim, porque se você interna uma paciente com $2 \mathrm{~cm}$ no único leito que tem e aí chega uma com $8 \mathrm{~cm}$ e aí, vai ficar aonde, no chão?" Ela chegou pra mim e falou isso. Então, quando..., teve uma vez que a gente mandou, né, uma paciente embora, eles ficaram assim revoltados...

M6-1 Porque às vezes ainda tem leito.

M7-4 Mas você tem que controlar os leitos, porque se você não controla, realmente é horrível, mas o que que você vai fazer? Entende? Tem que ter isso. Eles ficaram assim revoltados e eu acho que eu já 'tava muito mais fria.

M7-4, orgulhosa de sua experiência obstétrica como acadêmica, desejosa de reconhecimento pelos pares e com prazer de ser veterana no grupo, é porta voz do discurso dos médicos da cena do plantão na maternidade, fazendo seu o argumento pragmático que decidiu uma ação.

$\mathrm{O}$ argumento pragmático transfere para a causa o valor das conseqüências. No caso, duas conseqüências se contrapõem. Na consideração de uma paciente com $8 \mathrm{~cm}$ de dilatação, cuja existência, se não hipotética, não permitiria escolha, pois imporia a imediata realiza- ção do parto pelos médicos, e como nos diz Perelman (1996) não se delibera quando a solução é necessária e não se argumenta contra a evidência; é o valor que é transferido para a causa da ação ou o motivo da escolha. Mas a paciente com $8 \mathrm{~cm}$ tem uma existência hipotética, provável, ao passo que a paciente com $2 \mathrm{~cm}$ não. O lugar da qualidade, que se refere ao valor do único, no caso, destacando-se o sentido de irreparável, irremediável, é colocado em confronto com o lugar do existente, que afirma a superioridade do que existe, do que é atual sobre o possível, e uma outra escolha foi indicada pelo grupo.

A mobilização de certa estrutura defensiva que permita a diferenciação da dor do outro sem cortar o laço de identificação com o paciente, assim como a questão da dor associada à quebra da onipotência, é trazida pelo grupo possibilitando uma ressignificação para o tão conhecido "se acostumar" na prática médica:

M6-2 Eu acho que existe uma diferença entre se tornar frio e se tornar dolorido. É aquilo... Chega uma hora que você se acostuma à dor também, porque levando tanta pancada, você assimila melhor aqueles golpes. Isso é diferente de se tornar uma pessoa fria.

No quarto tema, o que está em foco é o relato do caso clínico e as práticas formativas, que implicam a construção da identidade médica articulada ao objeto do olhar e do discurso médicos. Os alunos vivem o conflito entre "ter que se acostumar" ou amplificar a voz desqualificada do paciente, entre o desejo de aprovação por seus pares e, ao mesmo tempo, a identificação com o paciente na experiência de sujeição que põe em questão os ideais e a ambição de cura. Muitas vezes, inclusive, o aluno vive um conflito mais intenso por se perceber como o principal destinatário da demanda do paciente. $\mathrm{Na}$ incerteza do difícil aprendizado da clínica, a distância entre a experiência narrada pelo paciente e o vivido pelo próprio aluno, com seu paciente e com seus superiores hierárquicos na enfermaria como no round, coloca a dúvida do aluno entre fato e ficção: o “paciente informa mal” e o aluno "está inventando ou viajando"? Ou a complexidade da clínica impõe uma investigação mais abrangente que a realizada nessa experiência ocorrida numa enfermaria de especialidade?

M7-1 ...Essa disfagia dela, ninguém... Acho que devem ter achado que é mentira minha, eu inventei. Porque eu já perguntei várias vezes, 
então: ah, de repente ela 'tá viajando, de repente ela não tem nada disso. Já perguntei. Já tentei caracterizar várias vezes. É verdade, sabe! A pessoa informa mal, mas ela não inventa a mesma coisa um milhão de vezes, entendeu, igual. Mas ninguém dá a mínima atenção pro que você fala, entendeu? A maior raiva. Dá até... nem dá vontade de você, pô você colhe a maior história enorme, sabe, examina o paciente, estuda, pra você perguntar as coisas e discutir, e ninguém te dá a menor atenção. [...] Não sei, de repente não existe mesmo, mas eu acho que tinha que ser estudado. [...] talar!

CM-3 Mais uma pneumonia e alta hospi-

\section{Considerações finais}

Ao investigarmos o que querem e o que podem querer estudantes de medicina, associando um método pedagógico a um método de pesquisa, acreditamos que o grupo de discussão produziu um saber que tende a ser dominado, desqualificado, uma vez que a ordem médica instituída limita, redutivamente, a prática discursiva à discussão da doença, como se a prática clínica e o ensino da clínica fossem meramente a aplicação de um saber sobre a doença num campo de certezas que não coloca para os médicos e estudantes a necessidade de realizar apreciações e escolhas, como se fosse possível não se confrontarem com a função de julgamento.

Ao associarmos os quatro temas, a desvalorização do sofrimento psíquico, a negação do corpo simbólico, o engendramento de uma identidade técnica e a experiência de sujeição de que nos falam os alunos, podemos surpreender uma coerência que nos remete, com Foucault (1985), à hipótese de uma estratégia sem estrategista presente na formação médica.

Esta estratégia reproduz a equação saber/poder que se descobre no discurso universitário e limita a transmissão do saber ao valor pragmático de eficácia da ação resolvendo a tensão doente/doença pela negação do doente. A experiência pedagógica que propusemos abre uma possibilidade de pesquisa que denuncia esta estratégia e mantém a tensão produtiva do questionamento, indicando a criatividade necessária em todos os momentos de realização do saber médico em uma prática clínica sempre complexa e extremamente difícil.

\section{Referências bibliográficas}

Bakhtin M 1981. Marxismo e filosofia da linguagem. Ed. Hucitec, São Paulo, 196 pp.

Eizirik CL 1994. Ensinando uma profissão impossível. Revista ABP-APAL 16(4):133-135.

Good BJ 1994. Medicine, rationality, and experience: an anthropological perspective. Cambridge University Press, Inglaterra, $242 \mathrm{pp}$.

Foucault M 1977a. O nascimento da clínica. Ed. ForenseUniversitária, Rio de Janeiro, 241 pp.

Foucault M 1977b. Vigiar e punir. Ed. Vozes, Petrópolis, 277 pp.

Foucault M 1985. História da sexualidade I: a vontade de saber. Ed. Graal, Rio de Janeiro, 152 pp.

Foucault M 1996. A ordem do discurso. Ed. Loyola, São Paulo, 79 pp.

Muniz JR \& Chazan LF 1992. Ensino de psicologia médica, pp. 37-44. In J Mello Fo (org.). Psicossomática hoje. Ed. Artes Médicas, Porto Alegre.

Perelman C \& Olbrechts-Tyteca L 1996. Tratado da argumentação: a nova retórica. Ed. Martins Fontes, São Paulo, 653 pp.

Souza Arnd 1998. Formação médica, racionalidade e experiência: o discurso médico e o ensino da clínica. Tese de doutorado. Instituto de Psiquiatria, Universidade Federal do Rio de Janeiro, Rio de Janeiro, 290 pp.

Zaidhaft S 1997. A saúde mental no hospital geral e seu impacto sobre a formação médica. Cadernos do IPUB 1(6):71-83. 